\title{
Toleration as Asymmetric Recognition
}

\author{
Tolerancia como reconocimiento asimétrico
}

Fabio MaCiOCE

LUMSA Università (Italia)

fmacioce@libero.it

RECIBIDO: 21/09/2017 / ACEPTADO 26/11/2017

\begin{abstract}
In this paper I argue for a conception of toleration as asymmetric recognition. I start from an analysis of the concept of toleration, and of the reasons that underpin such an act; then, the distinction between toleration and recognition is highlighted, and it is linked both to the different degree of cogency that these reasons reveal, and to the different structure of the relationship between the subjects involved. I argue that toleration is a form of asymmetric relationship, that may be granted with regard to 'divergent' practices because of the condition of vulnerability of the claimant group, rather than in virtue of their intrinsic value.
\end{abstract}

Keywords: toleration; recognition; asymmetry; vulnerability; minority groups.

\begin{abstract}
Resumen: En este trabajo defiendo una concepción de la tolerancia como reconocimiento asimétrico. Parto de un análisis del concepto de tolerancia y de las razones que sustentan dicho acto; luego, se resalta la distinción entre tolerancia y reconocimiento, los vinculando tanto al diferente grado de fuerza que revelan estas razones, como a la diferente estructura de la relación entre los sujetos involucrados. Argumento que la tolerancia es una forma de relación asimétrica, que puede otorgarse con respecto a las prácticas «divergentes» debido a la condición de vulnerabilidad del grupo demandante, más que en virtud de su valor intrínseco.
\end{abstract}

Palabras clave: tolerancia; reconocimiento; asimetría; vulnerabilidad; minorías

\section{INTRODUCTION}

I speaking of toleration, my aim is to deal with it as a legal and philosophical problem. More precisely, my aim is to demonstrate that toleration is rooted on the same reasons that underpin policies of recognition, but it goes a step forward. While the dialectic of reciprocity underpins the paradigm of recognition, toleration is required for a number of radical differences that are beyond the range of what we can recognise and accommodate. To do that, we should adopt a more asymmetric conception of toleration: such a conception, I admit, is similar to that of vertical permission, notwithstanding it stems from different reasons and reaches different results.

A number of caveat must be stressed. First, as I have stated above, I will consider toleration not as a subjective virtue, but as a public policy, that is as a concrete action towards practices and beliefs that are, for many reasons, different from the 'normality'. While English is much precise in distinguishing 
tolerance (as a form of personal behaviour) from toleration (the act or rule by which individuals and groups living in a given territory are granted to live according to their beliefs and to practice their particular religion), other languages (like Italian, or German, or Spanish, or French) use a same word for both: tolleranza, Toleranz, tolerancia, tolèrance. Thus, I must specify that in the present paper I will consider only toleration, leaving tolerance on the background, even if these two notions are clearly interrelated.

Second, I will focus on groups, rather than on individuals; not only because this is precisely what is more urgent in the context I am considering (Europe, mainly), but also because toleration of 'strange' or 'divergent' individual practices is -to my eyes- adequately ruled within the classical liberal paradigm $^{1}$. Third, I will analyse toleration in its vertical understanding (that is, within the relationship between the state and the minority groups that are settled in its territory): I will neither take inter-group toleration into account, nor form of toleration between states in the international context. For these reasons, my analysis will concern toleration as a public policy towards minority groups' claims in diverse societies.

\section{The Concept of Toleration}

Before going further in the discussion, it would be useful to better define both the concept and the conceptions of toleration that I will take into consideration. It is true, indeed, that toleration is a classical paradigm through which liberal democratic countries deal with differences, and first of all with religious differences; but at the same time both the subjects and the object of toleration are not easily clear-cut.

As a matter of fact, the term toleration can be applied to many different sorts of things, and between different subjects: we can talk about toleration in different fields and with regard to different topics, like religious beliefs,

1 For a survey on the liberal account of toleration see MENDUs, S., Toleration and the Limits of Liberalism, Atlantic Highlands, NJ, Humanities Press International, Inc., 1989, pp. 6 ss; GALEOTTI, A., La Tolleranza. Una proposta pluralista Liguori, , Napoli, 1994, pp. 35 ss; and ID., Toleration as Recognition, Cambridge University Press, Cambridge, pp. 21 ss; RaWLs, J., Political Liberalism, Columbia University Press, New York, 1996, pp. xxvi ss.; KuKaTHas, C., «Liberal Toleration», in Kukathas C. (ed.), The Liberal Archipelago: A Theory of Diversity and Freedom, Oxford University Press, Oxford, 2003, ch. 4. 
cultural practices, traditional behaviours, strange or hateful forms of speech. Again, we can tolerate these expressions of diversity in a number of ways, such as through legal norms and exemptions, or through socially shared behaviours, and these forms can be differently interrelated to each other depending on local circumstances. In other words, even if we focus on toleration rather than on tolerance (that is, on the specific acts and rules that grant individuals and groups the possibility to live differently and to practice their divergent way of life), there are different objects of toleration that can be considered, and different subjects that may tolerate (the international community, the state, the local authorities, other individuals $)^{2}$. Thus, finding a core concept of toleration, behind these different possibilities, is of utmost importance in order to proceed with the analysis of different conceptions of toleration, and of their merits in super-diverse societies ${ }^{3}$.

In a first perspective, the concept of toleration stems from the relationship between two different regulatory systems: it is the outcome of the interplay between a norm of a regulatory system (that prohibits or qualifies wrong a given practice / belief), and a superior system, which contains a norm (a principle, or a value, or a specific rule) that derogates to the first one ${ }^{4}$. More precisely, toleration is the outcome of a double normative qualification: on the one hand, what is tolerated is prima facie prohibited within the normative system of reference, that we can call the 'Basic' normative system. On the other hand, there must be a different and superior system, that we can label as the 'Justifying' normative system, according to which the former qualification (the prohibition) is overcame though not abolished ${ }^{5}$. This second and superior normative system provides principles and rules, which are the reasons for tolerating what is -according to the Basic system- prohibited: «toleration always presupposes an inter-system relation; intra-systemic toleration would be contradictory. ${ }^{6}$ Finally, toleration is (always?) a precarious balance: like for a number of sexual behaviours and orientations, some acts that were prohibited in the past Basic

2 Cohen, A. J., «What Toleration Is», Ethics (Oct. 2004), p. 70.

3 For an analysis of the term «superdiversity» as the key feature of contemporary Western societies, see VerTOVEC, S., «Super-diversity and its implications», Ethnic and Racial Studies, 29(6) (2007), pp. 1024-54.

4 Comanducci, P., «Sobre el problema de la tolerancia», Ideas \& Derecho, 1 (2001), p. 200.

5 GARZON VALDÈs, E., «Some remarks on the concept of toleration», Ratio furis, 10 (2) (1997), p. 130.

6 Ibid., p. 133. 
system, and then merely tolerated according the Justifying system, became fully allowed by the Basic system itself once they have been regarded in a different light. Thus, they currently do not need any kind of toleration.

In a second perspective, the concept of toleration should be analysed considering (at least) five characteristics ${ }^{7}$ : I will summarise them, and I will argue that this second account is much more precise and useful to understand the exact meaning of the concept. First, the vertical and/or horizontal relationship between tolerator and tolerated should be specified, as well as the object (beliefs, practices, etc.) of toleration. Second, we must suppose that the tolerated practices, beliefs, or acts are objectionable, some way or another, that is non-indifferent for those who tolerate them: this is the so called objection component, namely is what distinguishes toleration from a generic non-interference. Third, even if objectionable or negative, there must be many (practical or theoretical) factors that provide reasons for acceptation, that is factors that encompass the action and beliefs tolerated, so as to make them acceptable though not positively evaluable ${ }^{8}$. At the same time, fourth, any form of toleration is accompanied by the idea of a limit: we can tolerate objectionable things, provided we make clear what lies beyond such a sphere of toleration, because is not covered by the conditions of acceptance. As Forst clearly states, this condition (of intolerability) needs not to be identical to what is merely objectionable: there are practices and beliefs that one may find wrong (that is objectionable) but can still accept, because they are covered by the acceptance condition: beyond that line, there is the realm of the intolerable, which is rejected because reasons for acceptation and tolerance are not strong enough'. Fifth, the exercise of toleration must be voluntary, since otherwise we should talk of suffering, endurance, or patience, rather than of toleration: the tolerator is the subject who is in the position of deciding whether or not tolerate anything, and to what extent, and for what reasons. He/she is in the position of establishing the limits of toleration, thus he/she cannot be compelled to do so. This is the reason why citizens in a European country do not properly tolerate those who are of a different religion, because the legal system, in

7 Forst, R., «The limits of toleration», Constellations, 11 (3) (2004), p. 314-315. See also ForsT, R., «Toleration, Justice and Reason», in MCKinnon, C. and Castiglione, D. (eds.), The Culture of Toleration in Diverse Societies, Manchester University Press, Manchester, 2003, pp. 71-85.

8 For both the objection component and the acceptation component see KING, P., Toleration, St Martin's Press, New York, 1976, Ch. 1.

9 Forst, R., Toleration, fustice and Reason, cit., p. 72. 
granting to anyone the freedom of religion and conscience, does compel them to 'accept' those who are -to their eyes- heretics or nonbelievers ${ }^{10}$ : they may suffer, or abstain from illegal behaviours (such as interfering with the freedom of worship or religion of other people), but they do not tolerate anything.

Such a concept is different to the first one, not only because it considers more factors and aspects of toleration: it is different because is specifies that the objectionable practices are made acceptable by a number of reasons, rather than norms. Indeed, the first concept understands toleration as the outcome between two normative systems, according to which the practices are only prima facie prohibited (within the Basic system), because they are actually allowed within the Justifying system. The difference is noteworthy, and it is even deeper when we consider the distinction between policies of toleration and policies accommodation. Such a distinction is not always evident, nor always taken into account: ${ }^{11}$ in my understanding of toleration it is, contrariwise, pivotal, because toleration begins where accommodation is not possible any more.

In other words, only two scenarios are possible: first, toleration and accommodation are synonyms, thus we are simply multiplying the concepts, with no real reason and utility; second, accommodation and toleration are different kind of policies. I think that they are significantly different: while through accommodation the rules of the Basic legal system are modified and adapted to the new scenario (that is, we fully accept the fact we live in a diverse society thus we change the legal system to make it consistent with such a new characteristic of our society), ${ }^{12}$ in the second they are not: the rules of the

10 Robert Churchill defines toleration, among other things, as «voluntary forbearance on the basis of reasons.» See Churchill, R. P., «On the Difference between Moral and Non-Moral Conceptions of Toleration: The Case for Toleration as an Individual Virtue,» in AMIN RAZAVI, M. and Ambuel, D. (eds.), Philosophy, Religion, and the Question of Intolerance, State University of New York Press, Albany, 1997, pp. 189-211.

11 For instance, it is not considered -better, it is neglected as a matter of principle- by these scholars who argue for a toleration as recognition of excluded minorities (among others, TAYLOR, C., GaleotTi, A. E., Toleration, cit., pp. 192 ss; JonEs, P., «Toleration, recognition and identity», Fournal of political philosophy, 14(2) (2006), pp. 123-143). Even if I share the most part of their arguments, I argue that toleration is something more, and something different, from policies of recognition aimed to the accommodation of minority cultures. For a more complex interplay between toleration and recognition, which stresses the distinction between persons and groups, on the one hand, and practices, on the other hand, see LAEGAARD, S. «Recognition and toleration: conflicting approaches to diversity in Education», Educational Philosophy and Theory, 42 (1) (2010), pp. 22-37.

12 For a survey of the different phases of multicultural policies, and of accommodation of minority groups, see KymLICKA, W., «The rise and fall of multiculturalism? New debates on inclusion and accommodation in diverse societies», International Social Science fournal, 61(199) (2010), pp. 97-112. 
Basic legal system remain the same, but they are partially or temporarily overcame for reasons that make them acceptable. We can also express that same distinction by referring to two degrees of recognition: policies of accommodation are the result of a full recognition and a full participation in the public sphere, which is modified to permit such a participation; on the other hand, acts of toleration are weaker forms of recognition, even if they stem from the same kind of claims. In that second case, recognition means only a provisional suspension of rules that prohibit a specific behaviour, or a different interpretation $^{13}$ of these rules in specific cases, but the rules are neither modified not replaced by new ones.

This is the reason why the Garzon-Valdès definition of toleration is not enough precise: if we consider toleration simply as the outcome of the interplay between two regulatory systems, according to which a number of practices are only prima facie prohibited, because they are actually allowed by a Justifying norm, the distinction between accommodation and toleration vanishes. If such a Justifying norm does exist, the Basic system must be modified and the practice in question must be allowed: we may debate what may be the better way to modify the Basic legal system (through exemptions, or through a different interpretation, or through a degree of autonomy granted to minorities, etc.), but such a kind of modification is what underpins any policy of accommodation. Thus, in that perspective is unclear why should we talk about toleration rather than of accommodation (or recognition).

Politics of accommodation are different to each other, and largely dependent on local factors and specific circumstances: these strategies of accommodation may be distinguished into different categories, ${ }^{14}$ such as policies of autonomy (that is policies that grant minorities a voice in decision making processes), policies of symbolic recognition (apologies for injustice in the past, or inclusion of minority cultures in school curricula), policies of protection (e.g. measures to preserve cultural and linguistic minorities from assimilation, through specific measures of sustain), exemptions from specific legal requirements (for instance the exemptions concerning the wearing of Sikh turbans), and policies of direct assistance (through funding or through affirmative ac-

13 For an analysis of the role of legal interpretation in multicultural policies, see MACIOCE, F., «Legal Pluralism, Ethno-Cultural Accomodation, and the Interpretation of Rights», Rivista di Filosofia del Diritto, 4(2) (2015), pp. 381-426.

14 Murphy, M., Multiculturalism: A Critical Introduction, Routledge, London-New York, 2012. 
tions). All these policies, even variously related to different national contexts, ${ }^{15}$ display a more or less extensive recognition of minority claims, and try to find a solution to the conflict between specific practices and the legal system: in other words, every policy of accommodation is a solution (maybe precarious) to the challenge posed by the identity of a specific minority, and the rules of the Basic legal system. One can think that some of these policies are better than others, or that some of them are better attuned with the specific characteristics of a given situation. However, these policies (or at least a number of them) are the outcome of processes of public recognition: minority claims are considered publicly relevant and worthy of consideration, and they are admitted to the public sphere, so as to transform, modify, accommodate, or adapt the rules that shaped it previously.

In my understanding, reasons for toleration are the same that urge us to publicly recognise minority claims (through policies of accommodation), but they are less relevant, that is not strong enough to justify a change of the Basic legal system. In both cases we face a number of claims arising from inequalities between groups, and more precisely between groups whose religious, cultural, or traditional identities are excluded from the public sphere in liberal societies. And in both cases these claims are not merely about freedom (of religion, of conscience, of living privately a number of practices and traditions), but they concern the discrimination which stems from the exclusion of a given group identity from the public sphere. The difference, even if not always clear-cut, is that in a number of cases minority claims are deemed strong enough to modify the old rules, and to become fully accepted in the public sphere, in other cases they are not, even if not completely undeserving. There is a space between full recognition and reject: this is the space for toleration.

What is not completely clear in Garzon-Valdès' definition is the nature of the Justifying system, because it appears as a «superior normative system ${ }^{16}$, that is more a system of constitutional rules than a generic system of

15 See for the British context Modood, T., Multicultural Politics. Racism, Ethnicity and Muslims in Britain, University of Minnesota Press, Minneapolis, MN, 2005; and also Modood T., Multiculturalism. A Civic Idea, Polity Press, Cambridge, MA, 2007. For a non-EU context see KYMLICKA, W., Liberalism, Community and Culture, Clarendon Press, Oxford, 1989; and TAYLOR, C., «The politics of recognition», in GUTMAN, A. (ed.), Multiculturalism. Examining the politics of recognition, Princeton University Press, Princeton NJ, 1994, pp. 25-74.

16 GaRZON-VAldÈs, E., Some remarks on the concept of toleration, cit., p. 130. 
reasons. But if a behaviour, apparently prohibited by a norm of the (Basic) legal system, is permitted according to a more systematic understanding of the interplay between the ordinary system and the constitutional system, it should be simply allowed within the system: it should not be merely tolerated. On the contrary, following Forst, we may understand the Justifying system as a meta-legal system of reasons (ethics principles, reasons of prudence, practical needs, etc.) that urges the sovereign to tolerate what is, from a legal point of view, prohibited.

Finally, the discussion also demonstrates that the concept of toleration is indeterminate, in the sense that it cannot determinate its contents and its limits: in other words, that concept provides us a structural (formal) definition of toleration, not a substantial one. The content of toleration, that is, the specific beliefs and acts we decide to tolerate, and the limits of toleration, depend on the interplay between the Basic and the Justifying systems: thus, they depend on the specific normative options ruled by these two interacting systems. For these reasons, Forst correctly describes the concept of toleration as a «normative dependent concept. $\gg^{17}$ Toleration depends on the specific reasons that those who hold the power (of deciding whether to tolerate or not) assume as worthy of consideration: that is, it depends on the reasons that are considered strong enough to tolerate what is prohibited.

In order to determinate the contents and limits of toleration, we must therefore move from an analysis of the concept, to a discussion of the different conceptions of toleration, that is of the different paradigms within which toleration receives its substance. These conceptions are, so to say, the theoretical and political resources, that we can use to explain why toleration may be regarded as a valuable practice, and to what extent it is consistent with the justifying reasons that make it worthy of appreciation. These reasons are, as I have argued, the same that justify the politics of recognition in diverse societies: however, these reasons are less relevant, or not relevant enough to justify full accommodation (that is: a modification, an exemption, a positive sustain, etc.), but merely that some rules are disregarded in the specific case. Therefore, two questions arise: first, we need to analyse what are these reasons, which may underpin both policies of recognition and options for toleration (even with a different level of strength); second, we must bet-

17 Forst, R., The limits of toleration, cit., p. 314. 
ter define the threshold between accommodation and toleration, that is the limit between these two options. I will explore the first question in the next section, and the second in the final section.

\section{REASONS For ReCOgNition, REASONS FOR TOleRation}

I argue that the permission conception, and the respect conception, are the two most relevant paradigms of toleration, at least in the sense that they are the two opposing poles of a wide range of possibilities within which we can justify and limit a tolerant policy. Such a distinction is also transversal to that between the different accounts of toleration such as the liberal, or the multicultural one: more precisely, the liberal understanding of toleration can be -depending on the single author- closer to one or another of these two poles. However, I will analyse only the conception of toleration-as-recognition, because I assume that the reasons, which underpin toleration and recognition, are basically the same, with only a different in intensity.

The conception of toleration-as-recognition stems from the idea of respect, and it shifts more resolutely from the idea of forbearance to the paradigm of recognition. Such a conception, as a matter of fact, takes the fact into account that both the toleration-as-permission, and the toleration-as-neutrality, are not able to provide adequate answers to quests for dignity, identity, survival and preservation posed by groups, rather than by single individuals, and that the formal recognition of equal rights in the public sphere is not enough.

State neutrality simply means that the rules governing the public sphere can be justified by reasons that must not be biased, and that heretic or divergent practices are permitted into the private realm: practices and beliefs are publicly accepted provided they are consistent with the rules and the principles established by the democratic majority (e.g. a number of constitutional principles), or with reasons accepted by them (practical reasons, political convenience, etc.) and tolerated to the extent they are restricted into the private sphere, not claiming for public recognition. It is the private sphere the place where political interference is suspended, that is a realm where the state has no reason to intervene with its coercion. ${ }^{18}$

18 See that Locke's statement: «It may indeed be alleged that the magistrate may make use of arguments, and, thereby; draw the heterodox into the way of truth, and procure their salvation. I 
What is at stake is that the neutrality principle «simply overlooks the public/private dimension that regulates the very working of the neutrality principle ${ }^{19}$ : as long as citizens are free to pursue their own ideals and to practice their culture in the private realm, and as long as in the public sphere they «should disregard their particular membership and be 'just citizens' on an equal basis» ${ }^{20}$, the fact of holding the power to draw the line between the public and the private realm is pivotal. As Galeotti states, not only modern democracies need to allow minority members the freedom of expression or the freedom of religion, but liberal states should also «counter the advantages or disadvantages that (they) have accumulated over a long period of discrimination». ${ }^{21}$ If minority members' beliefs and practices are tolerated in the sense of the mere permission, and if they are relegated into the private realm, without allowing them any form of public recognition, substantial equality is missed: members of these groups are not equals to members of the majority, because they do not enjoy public respect.

The private/public distinction is in itself not neutral with respect to the plurality of beliefs and practices found in diverse societies, but it reflects the values and the conception of the dominant majority. Even the most basic concepts, such as those of human nature, human body, birth and death, and rationality, are to some extent culturally embedded, and different cultures have different conceptions with regard to issues such as the children's education or the periodization of life, and so on. ${ }^{22}$ Our very understanding of human rights, that is, of those rights that we should grant to ethno-cultural groups, is shaped by certain ideas of happiness, wellbeing, autonomy, and freedom, which are themselves culturally formed and cultivated. ${ }^{23}$

grant it; but this is common to him with other men. In teaching, instructing, and redressing the erroneous by reason, he may certainly do what becomes any good man to do... Every man has commission to admonish, exhort, convince another of error, and, by reasoning, to draw him into truth; but to give laws, receive obedience, and compel with the sword, belongs to none but the magistrate. And, upon this ground, I affirm that the magistrate's power extends not to the establishing of any articles of faith, or forms of worship, by the force of his laws. For laws are of no force at all without penalties, and penalties in this case are absolutely impertinent, because they are not proper to convince the mind.» LOCKE, J., Second Treatise of Government and A Letter Concerning Toleration, Ed. by Mark Goldie (Oxford University Press, 2016), p. 129.

19 Galeotti, A. E., «Citizenship and equality: The place for toleration», Political Theory, 21 (4) (1993), p. 592.

20 Ibidem.

21 Galeotti, A. E., Toleration as Recognition, cit., p. 65.

22 ParekH, B., Rethinking Multiculturalism. Cultural Diversity and Political Theory, Macmillan, Basingstoke, 2006, p. 121.

23 Ibid., p. 109 ff. 
Moreover, not for everyone the withdrawal of his/her own membership is equally easy: the pressure of the state can be different for those who belong to minority groups, that is for those who experience the pressure of other loyalties and other memberships, beside that of the state. In other words, the majority has the power to draw the line between the public and the private sphere, so as to affirm the loyalty to the state as the only relevant loyalty in the public realm; the minorities do not have such a kind of power, being only subjects to such a distinction, and not being able to contest it. ${ }^{24}$

By reason of that inadequacy, a stronger form of recognition must be joined with the practice of toleration: if a given diversity (for instance, a religious diversity) is relegated to the private realm, it is denied equal public legitimacy with other forms of belonging (for instance, the political identity) and with other creeds. ${ }^{25}$ Therefore, in so far as that diversity is related to a minority, and it is part of the minority's identity, the group associated with it does bear a social stigma: its members lack a crucial condition for self-esteem and wellbeing. ${ }^{26}$

For these reasons, toleration-as-recognition demands to consider the 'others' as partners of a relationship of reciprocal recognition. Those whose beliefs and practices are 'different', are recognised morally and politically equals, even if they hold in many respects a number of incompatible views: not only they are free and equals in the public sphere, in the sense they are entitled to the same set of rights as anyone else, but the whole society is available to forms of mutual adaptation in order to leave room to group identities. Diversities are not simply confined in the private realm, and individuals who

24 Such a kind of privilege is not exclusively related to cultural minorities. As Young correctly observed, «dominant institutions support norms and expectations that privilege some groups and render others deviant. Some of these are cultural norms, but others are norms of capability, social role, sexual desire, or location in the division of labour». See Young, I.M., «Ruling Norms and the Politics of Difference: A Comment on Seyla Benhabib», The Yale fournal of Criticism, 12 (2) (1999), p. 415.

25 A classic example of this position is RAWLS, J., «The idea of an overlapping consensus», Oxford Fournal of Legal Studies, 7 (1987), pp. 1-25, and ID., «The Priority of the Right and the Idea of the Good», Philosophy and Public Affairs, 17 (1988), pp. 251-276; but the argument is clearly and classically stated in LocKE, J., A letter, cit., p. 233: «The church and the worship of God is outside] the reach of the magistrate's jurisdiction, because [...] they have no connexion at all with civil affairs. The only business of the church is the salvation of souls: and it no ways concerns the commonwealth». See more recently JONES, P., «Toleration, recognition and identity», fournal of political philosophy, 14 (2) (2006), pp. 123-143.

26 GaleotTi, A.E., Citizenship..., cit., p. 597. 
belong to a minority group do not bear any kind of social stigma. Differences should not be merely tolerated as private lifestyles, but accepted so as to symbolically recognise their public presence. Authentic recognition concerns the fully inclusion of minority and weak groups, within democratic citizenship by virtue and not in spite of their membership, and the identity of the group. ${ }^{27}$

Of course, not everything can be recognized: not every practice can obtain a public recognition, even if it may be part of the identity of a group. Because it would be inconsistent with the paradigm of recognition limiting toleration only with reference to the values of the majority, the strategy must here be different: many authors draw the line of toleration using the principle of justification, or the paradigm of constitutional patriotism. ${ }^{28}$ Minorities and groups involved in the relationship of recognition are asked to respect these principles of practical reason they themselves need to take recourse when they claim for recognition. If any conception of the good is allowed to participate in the public debate, and if they interact to each other within a framework of rules that give to each actor equal chances to raise claims (that is, both to minorities and to majority), the respect of the rules governing the public space is pivotal. More precisely, what is pivotal is the respect of the principle of reasonable justification, that is the principle according to which arguments for and against any conception must be mutually justifiable, and not based on a prejudicial denial of what is different. The acceptance of that principle draws the limits of the tolerable, and thus defines what may be recognized, and what may not, for those who deny it deny the basic norms of dialogue and democratic coexistence. ${ }^{29}$

However, I will argue that even if is perfectly reasonable to limit the possibilities of recognition by using the principle of public justification, or the

27 Lukes, S., «Toleration as recognition», Ratio furis, 10 (2) (1997), p. 215. See also GaLEOTTI, La tolleranza, cit., p. 153.

28 The most prominent paradigm is here the Habermas' idea of a «discourse ethics». See his Moral Consciousness and Communicative Action, trans. Lenhardt, C. and NiCHOlSERT, S.W., MIT Press, Boston, 1990. For the idea of constitutional patriotism see Habermas, J., The New Conservatism: Cultural Criticism and the Historians' Debate, MIT, Boston, 1989, p. 236; and HABERMAS, J., «Citizenship and National Identity. Some Reflections on the Future of Europe», in R. BeINER (ed.), Theorizing Citizenship, State University of New York Press, New York, 1999, p. 278. More recently, for further analyses, see CalHoun, C., «Imagining Solidarity: Cosmopolitanism, Constitutional Patriotism, and the Public Sphere», Public Culture, 14 (1) (2002), pp. 147-171.

29 See, on that perspective, FORST, R., The right to justification. Elements of a constructive theory of justice, Columbia University Press, 1997, pp. 79 ff., 139 ff. 
paradigm of constitutional patriotism, they are less relevant as a criterion for toleration. In other words, these criteria may well define what can be recognised in liberal societies, and thus accommodated, but toleration lies beyond the limit of recognition: with regard to toleration, the paradigm of constitutional patriotism is only the lower limit, not the upper one.

\section{The Limits of Recognition And the Borderline BETWEEN RECOGNITION AND TOLERATION}

Affirming that the principle of reasonable justification is the limit of what we can recognised, is consistent -not by chance- with the idea of constitutional patriotism, ${ }^{30}$ according to which the pluralism of our societies is limited by the respect (and the sharing) of the basic principles of our legal and social systems: failing to comply with them is not at all tolerable. According to that perspective, the ethno-religious diversity does involve recognition but also requires that all the parties involved take the perspective of the other, in so making the diversity itself rationally acceptable for both. ${ }^{31}$ As Habermas clearly states, minority groups «do not enjoy equal cultural rights free of charge $»^{32}$ : multiculturalism does not merely mean the recognition of collective identities claimed by minority groups, but it also requires the integration of individuals and groups within the common political culture. That is, within the framework of principles and rules, which defines the boundaries of the social order, and the limits of what we may recognise: citizens are empowered to maintain their cultural identity «under the supposition that along with all the others they understand themselves as citizens of the same political community.» ${ }^{33}$ When diversity concerns different world views, the accepting a same set of basic principles is the prerequisite of any kind of recognition.

It is true that such a set of principles is not necessarily a list of principles concerning justice or a substantial vision of the common good (such

\footnotetext{
30 Habermas, J., «Struggles for Recognition in the Democratic Constitutional State», in GUTMANN A. (ed.), Multiculturalism, cit., pp. 122 ss. That model has also been discussed in HABERMAS, J., Eine Art Shadensabwicklung. Kleine politische Schriften, VI, Suhrkamp, Fr. am M, 1987.

31 HABERMAS, J., «Intolerance and discrimination», International fournal of Constitutional Law, 1(1) (2003), p. 5.

32 Ibid., p. 10.

33 Ibid., p. 11.
} 
as the fundamental rights guaranteed in constitutional charters). According to so called 'Discourse-Ethical' foundation of tolerance, recognition is given within a framework of principles that lie at the basis of the correct procedures of practical discourse: these procedures that are grounded on the undeniable presupposition of reasoning and argumentation ${ }^{34}$. However, since the basic principles of the modern liberal democracies are consistent with the discourse-ethical account, and since the procedures of modern liberal democracies seem to be the best realization of the procedures for a public discourse, the constitutional patriotism and the undeniable presuppositions of public debate are the two coins of a same medal. For the sake of social cohesion, it is not necessary for citizens to share a number of moral ideals and values; civic virtues are in fact formal virtues. Integration among citizens is achieved through the sharing of a democratic model within which the freedom of communication in the public sphere, the possibility of controlling the legitimacy of the power, the possibility of resolving conflicts through democratic procedures, are the core of a procedural consensus that goes beyond, and holds together the many alternative conceptions claiming for recognition. ${ }^{35}$

These conditions undoubtedly express a search for consensus and mutual understanding among persons, and tend to create a space of mutuality and reciprocity either in a substantial sense (by referring to a list of basic constitutional values) or formally (by referring to the rules and procedures of the discourse). As Young rightly affirmed, they express «a desire for social wholeness, symmetry, a security and solid identity which is objectified because affirmed by others unambiguously. This is an understandable dream, but a dream nevertheless» ${ }^{36}$.

As a matter of fact, limiting recognition to what does not go beyond a list of core values and procedures, which defines our shared vision of the community we want, means excluding precisely those who are experienced as too different, so as to value and enforce social homogeneity. In other words, it means limiting recognition to these differences that in a pluralistic society are already

34 APEL, K.O., «Plurality of the good? The problem of affirmative tolerance in a multicultural society from an ethical point of view», Ratio furis, 10 (2) (1997), p. 208.

35 See Habermas, J., Struggles for Recognition, cit., p. 135. For an analysis of the link between citizenship and participation to a common frame work of values, by the mean of the public debate, see van Gunsteren, H.R., «Admission to Citizenship», in Ethics, 98 (1988), pp. $731 \mathrm{ff}$.

36 Young, I. M., Fustice and the Politics of Difference, Princeton University Press, Princeton, 2011, p. 231. 
allowed (through the freedom of religion, worship and conscience, freedom of association, the principle of non-discrimination, etc.). What is starkly different, what expresses a stark otherness to our identity, is asked to become homogeneous to us, and to accept the basic values of our culture, otherwise it is deemed as intolerably different.

The ideal of a principled symmetry of any participant to the public discourse is, as Young correctly states, an ideal picture of the real interaction between different identities. Not only the image of a symmetrical effort to comply with democratic procedures and discourse ethics tends to neglect the difference and the particularity of the other's position, and does not consider the context of interaction, but it does «involve members of socially and culturally differentiated groups that also stand in specific relations of privilege and oppression with respect to one another. $\gg{ }^{37}$ What is more important, such a paradigm imposes an additional burden precisely on those who are in the more vulnerable position, asking them to translate their claims into paradigms of rationality and reasonableness that might not belong to them. As Habermas himself recognized in a widely known article, the liberal state can neither expect of all citizens that they justify their claims independently of their religious convictions or world views, nor that every participant to the public discourse is obligated to supplement his/her public statements of cultural and religious convictions by equivalents in a generally accessible language ${ }^{38}$.

This is the reason why the idea of a toleration conditioned to the acceptation of the basic principles of the discourse ethics is either too little, or too much $^{39}$ : and this is the reason why I draw here the line between recognition (and accommodation) and toleration. If toleration does mean that the state must recognize the principle of the freedom of communication in the public sphere, and the possibility of controlling the legitimacy of the power, it is too vague to provide solutions to concrete problems. If, on the contrary, it does mean that the tolerated (or the would-be tolerated) claims are to be justified in the public arena through arguments and reasons that are consistent to the

37 ID., «Asymmetrical Reciprocity: on Moral Respect, Wonder, and Enlarged Thought», Constellations, 3 (3) (1997), p. 349.

38 Habermas, J., «Religion in the public sphere», European fournal of Philosophy, 14 (1) (2006), p. 9.

39 For an in-depth analysis of the critical aspects of such an ideal, according to which we would be able to find a shared and reasonable solution to the problems of pluralism, see WALDRON, J., «Toleration and reasonableness», in MCKINNON, C. and CASTigLione, D., The culture of toleration, cit., pp. 21-34. 
principles of discourse ethics, it demands too much. In that second hypothesis, the liberal state would impose an undue psychological burden on those citizens whose practices and world views are rooted on a faith, or on a traditional culture: they would be allowed to express and justify their convictions only provided they were able to translate them into rationally understandable arguments. But, as Habermas admits, we need not to «estrange 'mono-glot' citizens from the political process», even if their religious or traditional language is the only one they can speak in public, and they should be fully perceived as members of the community, because «we should not over-hastily reduce the polyphonic complexity of public voices». ${ }^{40}$

In sum, as Raimon Panikkar correctly stated, toleration begins where parties recognize themselves as really and decisively different to each other. What is at stake is always the question of the intolerable: the pluralism arises in the area of what is not negotiable for us. All the rest is a matter of acceptance, or compromise, or savoir-faire ${ }^{41}$. To the limit that majority and minority groups are able to admit the same principles, and to structure their arguments in the same way, even if their claims are different, they do not need toleration: they do recognise each other. Thus, limiting toleration with the proviso of the acceptation of discourse ethics, and/or of basic principles of our constitutional charters, does mean limiting toleration to what is so similar that it does not need any real toleration: toleration does not end here, rather it begins here.

\section{Toleration as Asymmetric ReCOGNition}

As I have explained above, if we want to maintain the difference between toleration and accommodation, we must consider toleration as starting precisely where recognition cannot be reciprocal anymore: it begins once we leave room for practices that are inconsistent with our own principles and rules. But if toleration begins where there is no reciprocity, then the structure of toleration is asymmetric.

To give a philosophical example, I consider toleration like an equivalent of the Levinas's understanding of the ethical relationship, in legal and po-

40 Habermas, J., Religion in the public sphere, cit., p. 10.

41 Panikkar, R., «The Myth of Pluralism: The Tower of Babel. A Meditation on Non-Violence», CrossCurrents, 29 (2) (1979), p. 207. 
litical issues: rather than asking for a common and mutual recognition, the relationship between subjects starts with an asymmetric responsibility for the actually embodied person (the visage). People's positions are neither reducible nor reciprocal to each other: the opening up to the Other is -in Levinas's account- always a gift. ${ }^{42}$ Similarly, I argue that toleration may be perceived as an asymmetric burden (even if not a gift): something that the majority should do, even if it may ask nothing (or little) in return, because toleration happens in a relationship of power imbalance. ${ }^{43}$

However, even if the majority may always decide not to tolerate, and not to leave room for a number of practices, I do not consider toleration as a simple act of grace. In other words, even if toleration is not properly owed (due to the power imbalance, and due to the consequent difficulty of asking for reciprocity), it is not arbitrary as well. There are reasons (within the Justifying system) that make toleration rightfully allowed, and reasons due to which toleration may not be allowed. In both cases, toleration is still granted or denied from an asymmetric position: but in the first case it is an act that the majority has good reasons to do, while in the second there are good reasons not to do it. ${ }^{44}$ The distinction

42 LÉvinas, E., Totalité et infini. Essai sur l'extériorité, Martinus Nijhoff, Paris-La Hague, 1961, p. 76; more precisely, Lévinas understands the human relationship as a form of passivity, which is linked to the vulnerability of the self: it is linked to «la corporéité humaine vivante, en tant que possibilité de la douleur -en tant que sensibilité qui est, de soi, la susceptibilité d'avoir malen tant que soi découvert, s'offrant, souffrant, dans sa peau -en tant que dans sa peau, mal dans sa peau, n'ayant pas sa peau à soi- en tant que vulnérabilité». LÉVINAS, E., Autrement qu'être ou au-delà de l'essence, Martinus Nijhoff, La Hague, 1974, pp. 86-87.

43 Forst stresses the need of a critical political theory, which implies an analysis of the «existing asymmetrical and biased «relations of justification» among members of a social and political basic structure, in terms of substance as well as of procedure». FORST, R., The Right to fustification, cit., p. 151.

44 In that sense, my approach to toleration answers to the criticisms expressed by Heyd concerning the current notions of toleration. He argues that if toleration is due according to a number of principles, it is not toleration anymore, properly speaking, being rather the recognition of a right: «Unlike a medieval sovereign, the state (...) cannot be engaged in toleration. The law either permits or prohibits certain practices and activities. The prohibited act cannot be tolerated by the law and the permitted practice cannot be said to be endured as a matter of charity or restraint. Thus, for example, the issue of Muslim female students wearing headscarves in French state schools is not really a matter of toleration but a question of the correct interpretation of constitutional principles and of the idea of the separation of state and religion.» In other words, according to Heyd, the legal status of minorities is a matter of rights rather than of toleration by the state. I fully subscribe that point: however, I argue that there are situations where minority practices and claims should be asymmetrically recognised, that is beyond any reference to specific state's duties. See HeYD, D., «Is toleration a political virtue?», in WILliams, M.S. and WaLDRON, J. (eds.) Toleration and its limits, New York University Press, New York and London, 2008, p. 178. 
between a mere grace-based toleration ${ }^{45}$, and the asymmetric toleration conception that I am proposing here, is precisely related to the presence of reasons that sustain the second, and that may be absent in the first one.

What is therefore at stake is, first, a definition of the reasons according to which toleration is justifiable, that is the reasons why a majority should tolerate deviant practices and minority claims. Second, a kind of threshold test would be necessary, in order to distinguish claims and practices that should be tolerated, from these that should be deemed intolerable.

As I have already discussed in the previous analysis, the basic reasons that underpin toleration, are the same which underpin the policies of recognition: a decent society ${ }^{46}$ is a society where everyone is not excluded by that context of recognition that are the basis for self-esteem and respect. To ask some individual to decide between his/her personal belonging, or identity, and the participation in public life as a full member of the whole community, is not consistent with such a standard of decency. A decent society is a place where membership is allowed by virtue and not in spite of individual identity. The difference, I must stress again, is that reasons for toleration are not strong enough to justify a full recognition (and a subsequent accommodation) of the practices under consideration: reasons are in that case less relevant and persuasive.

However, if toleration begins where accommodation is not completely possible, or desirable, one may ask why the state should not simply reject the claims that it did not consider worthy of a full recognition. In other words, if a state (better: a majority) is not willing to change its rules, so as to recognise the minorities' claims, it might have reasons to consider these claims as strongly inconsistent to its rules, and its basic principles. Thus, these claims should simply be rejected. I argue that there might be situations where an intermediate solution would be justified: that is, more just and fair. ${ }^{47}$

45 See Yovel, Y., «Tolerance as Grace and as Rightful Recognition,» Social Research, 65 (1998), pp. 897-919.

46 Margalit, A., The decent society, Harvard University Press, Cambridge: Mass., 1998.

47 Such a third path is risky, because it exposes the parties to the possibility of failure; however, asking to overcome the logic of reciprocity, it opens new spaces for the permeability of identities, for their critical exam, as well as it gives to the others the opportunity to promote the hybridation of the mainstream culture. For an analysis of the risks and opportunities of toleration, see Giolo, O., «L'urgenza della tolleranza», Ragion Pratica, 2 (2006), pp. 437438. 
These situations concern claims advanced by particularly vulnerable groups, that is by minority groups that not only are in a position of social exclusion, but that are also particularly vulnerable.

In other words, I suggest to use the concept of vulnerability as a threshold test: only those groups that are, for different reasons, in a condition of specific vulnerability should be tolerated, and should receive special consideration and protection even beyond the limits of the policies of recognition. Vulnerability may play the role of the justificatory reason that urges for toleration, even beyond the limit of what should be fully recognised and accepted in the public sphere. But what is the meaning of vulnerability, and what should be its role in issues related to minority groups' claims?

Vulnerability is, according to the definition provided by the United $\mathrm{Na}-$ tions Department of Economic and Social Affairs, an «integral part of the human condition», thus able to influence both individuals and organizations. More specifically, it is «a state of high exposure to risks and uncertainties, in combination with a reduced ability to protect or defend oneself against those risks and uncertainties and cope with the negative consequences». ${ }^{48}$

Such a definition is consistent to what many scholars argued, ${ }^{49}$ by affirming that the term describes, at the same time, both a universal aspect of the human condition, and a peculiar condition of single individuals or groups. Human vulnerability arises not merely from the vulnerability of the body, but concerns at the same time the co-existential, social nature of human life, and the constant potential for dependency: the human being is a Mängelwesen, ${ }^{50} \mathrm{a}$ deficient being who is constantly in need. The co-existential and social dimension of our lives position us differently within many personal, economic, legal and political relationships, thus our vulnerabilities range in magnitude and potential at the individual level. ${ }^{51}$ Vulnerability is thus a «relational» concept, which adds «attention to the individual subject by placing him/her in social

48 United Nations Department of Economic and Social Affairs, United Nations Report on the World Social Situation: Social Vulnerability: Sources and Challenges (New York: 2003).

49 See, among others, FinEMAN, M. A., «The Vulnerable Subject: Anchoring Equality in the Human Condition», Yale fournal of Law \& Feminism, 20 (2008), pp. 251-273. BuTLER, J., Precarious Life: The Powers of Mourning and Violence, Verso, London, 2004. TURnER, B. S., Vulnerability and Human Rights, The Pennsylvania State University Press, University Park: PA, 2006.

50 Gehlen, A., Man: His Nature and Place in the World, trans. McMillan, C. and Pillemen, K., Columbia University Press, New York, 1988, p. 13.

51 Fineman, M.A, The vulnerable subject, cit., p. 10. 
context»: $:^{52}$ it is related to the fact that we are subjects to the «whim of another», and that we may not even know the people on whom our lives depend. ${ }^{53}$

For this reason, even if every human being is vulnerable, everyone experiences his/her vulnerability in a different manner, depending on the resources (interpersonal, legal, economic, etc.) he/she possesses or is entitled to. ${ }^{54} \mathrm{In}$ other words, our ability in facing vulnerability is related to a wide range of social assets, that are the networks of relationships within which we live, and from which we receive support: families, associations, trade unions, religious groups, etc. And even if public institutions do not directly provide these networks, their action is deeply conditioned by policies and rules that define and govern them.

Additionally, even if every human being is vulnerable, not everyone is vulnerable in the same way, nor to the same measure. Some people, due to their specific group membership, are marked by specific and particularly strong forms of vulnerability. What are these forms? I argue that we may use, in determine whether we face a group that experience a particularly strong form of vulnerability, the standard test adopted by the ECtHR in a number of cases, which takes the criteria of relationality, particularity, and harm into consideration. ${ }^{55}$

Group's vulnerability is relational, because it is referred to the social context: to put it more directly, group vulnerability is related to social, historical, and institutional forces, that should be taken into account in determining its measure and its potentiality of harm. Some form of prejudice and stigma, for instance, can originate and sustain the vulnerability of a single group of people: they are peculiar to the condition of such a group, and affects their enjoyment of fundamental rights and social goods. Accordingly, in D.H. and

52 Ibid., p. 13.

53 Butler, J., Precarious Life, cit., p. vii.

54 These resources can be classified in (at least) three main groups: material assets, human assets, and social assets. Institutions can provide us with goods that shape our quality of life, like economic resources, taxes, subsidies, but also credit policies and inheritance rules: these are examples of material assets. See KIRBY, P., Vulnerability and Violence. The impact of Globalization, Pluto Press, London, 2005, p. 55. Also institutions may influence our human assets, that are our human capital or our capabilities, through health care system, education, employment services, etc. See Nussbaum, M.C., Frontiers of Fustice: disability, nationality, species membership, Belknap Press, Cambridge: MA - London, 2006, p. 70 and p. 164.

55 Peroni, L., and Timmer, A., «Vulnerable groups: The promise of an emerging concept in European Human Rights Convention law», International Fournal of Constitutional Law, 11 (2013), p. 1064. 
Others v. the Czech Republic, the Court stated that Roma have become a specific type of vulnerable minority as «a result of their turbulent history and constant uprooting». ${ }^{56}$

Consequently, group vulnerability is shaped by specific group-based experiences. Neither every disadvantaged group is vulnerable in the same way, nor every social or historical circumstance produces the same kind of vulnerability. This is the reason why the Court considers with specific attention «particularly vulnerable groups», ${ }^{57}$ where the term 'particularly' stresses that specific protections are allowed to specific needs, and that the considered groups are those more in need.

Finally, the main indicator of such a particular vulnerability is the harm produced by historical forms of prejudice, by misrecognition, and by patterns of cultural devaluation that produce specific form of discrimination, social disadvantage, or material deprivation. In that perspective, an analysis of applicant's living condition (thus, a case by case analysis) can determine if, and to what extent, he/she belongs to a particularly underprivileged and vulnerable group, thus in need of special protection by states and institutions. In M.S.S. v. Belgium and Greece, ${ }^{58}$ for instance, the Court grounded its analysis on the consideration of the daily reality of asylum seekers in Greece, their dependence on the state, the trauma they experienced during the process of migration, and the deficiencies of the Greek asylum system. ${ }^{59}$ It is not a mere condition if misrecognition that counts, but a harmful condition of misrecognition, deprivation, and discrimination.

Such an approach is consistent to the Heyd's claim for treating toleration «as involving a perceptual shift: from beliefs to the subject holding them, or from actions to their agent». Toleration, in that perspective, is granted not because the considered practices have an intrinsic value as such, but because the majority acknowledges the agent's intrinsic attachment to these values ${ }^{60}$ and takes the specific group vulnerability into consideration.

56 D.H. and others v. the Czech Republic (GC), App. No. 57325/00.

57 Alajos Kiss v. Hungary, App. No. 38832/06.

58 M.S.S. v. Belgium AND GrEeCE, App. No. 30696/09.

59 Peroni, L., «Vulnerable groups», cit., p. 1069.

60 HeYD, D., «Introduction», in HEYD, D. (ed.), Toleration: An Elusive Virtue, Princeton University Press, Princeton, 1996, pp. 11-13. The importance of a perceptual shift is -even if differently- also argued by Nussbaum: according to her perspective, toleration needs (in order to be concretely achieved, and not only theoretically defended) a radical change in people's attitudes: «the problem cannot be resolved without careful thought about how a liberal state can cultivate 
Such a consideration of the particularly vulnerable condition of minority groups does not imply, per se, toleration. It merely implies that the reason not to tolerate a specific practice must be examined under a closer scrutiny: every decision about tolerating or not, should start from an aprioristic favour towards vulnerable groups' claims, whose condition acts as a «magnifying glass ${ }^{61}$ through which every deprivation, every discrimination, and every choice about detention or expulsion looks bigger. Those who hold the power to tolerate (or not), must exhibit their reasons, and must demonstrate that the groups' specific vulnerabilities have been taken into consideration, otherwise their choices will be deemed unreasonable. ${ }^{62}$

We might consider, for instance, the so called «caravan cases»: according to the Court, due to the ascertained Roma's vulnerability, states are to a certain extent under the obligation to facilitate their lifestyle. ${ }^{63}$ For that reason, states may recognise the claims advanced by Roma groups, and allow them to live according to their lifestyle. In this cases, states do fully (or partially) recognise a minority culture and its practices, and they do modify the rules of the Basic system so as to leave room for a group that is divergent from the mainstream culture: to the extent such an accommodation is allowed with the proviso that the group accept the integration within a common framework of principles and rules, this is not an example of toleration, but a policy of recognition. ${ }^{64}$

emotions that support equal respect and a toleration that is more than grudging obedience to law», see Nussbaum, M., «Radical Evil in the Lockean State: The Neglect of the Political Emotions», Fournal of Moral Philosophy, 3 (2) (2006), pp. 159-178. In a similar sense, Wolff argues for the relation between the specific social ethos, and the kind of tolerating response to minorities' claims: see WolfF, J. «Social ethos and the dynamics of toleration», in MCKINNON, C. and Castilione, D., The culture of toleration, cit., p. 151.

61 Peroni, L., Vulnerable groups, cit., p. 1079.

62 A similar approach to that I am arguing for, has been discussed by Meital Pinto, with specific regard to the vulnerability of religious groups, and -more in general- to the merits of using vulnerability as a criterion to balance neutral liberalism, on the one hand, and the protection of cultural identities, on the other hand. See PINTO, M., «What Are Offences to Feelings Really About? A New Regulative Principle for the Multicultural Era», Oxford Fournal of Legal Studies, 30 (4) (2010), pp. 695-723.

63 Connors v. United KIngdom, App. No. 66746/01, par. 84: «The vulnerable position of gypsies as a minority means that some special consideration should be given to their needs and their different lifestyle both in the relevant regulatory framework and in reaching decisions in particular cases»; see also SMITH v. UnITED Kingdom, App. No. 25154/94; BEARD v. UnITED KINGDOM, App. No. 24882/94.

64 It must be stressed that such a positive obligation to facilitate Roma lifestyle does not mean that minority members are allowed to live according to their culture, because the obligation is procedural: «As intimated in Buckley, the vulnerable position of Gypsies as a minority means that 
On the contrary, state authorities may consider a specific practice inconsistent with the basic principles of the legal system, and not deserving special policies of recognition and accommodation: thus, as not deserving any amendment of the rules of the Basic system, because the reasons of the Justifying system are not strong enough: this is for instance the case of female genital mutilation, that must not be recognised at all.

There is a third possibility, however. Such a third option may take place in cases where the breach of the Basic system must not be overcame, because we lack reasons strong enough to justify a policy of accommodation, but there are other reasons that make unreasonable a blunt refusal: first, the practice is claimed as part of the identity of a particularly vulnerable group. Second, it does not endanger the fundamental rights of other people. One may consider the definition of «adulthood» and the limits to marriage, or the definition of what a 'mature' minor is, for example with regard to the expression of consent to medical treatments. In both cases, we should recognise that the minimum age at which a person is allowed to marry is often set at 18, at least in many European countries, ${ }^{65}$ and that different limits are set for specific activities, like driving, smoking, giving a valid sexual consent, etc. These age limits are reasonable, of course, and there might be no reasons to change them: but, at the same time, they are largely contingent, depending on what the mainstream culture consider the right moment should a person decide for herself. I argue that issues related to cultural definitions of adulthood may be good objects of toleration: not in the sense that any cultural claim must be tolerated, but in the sense that state authorities, in deciding how to deal with these claims, must show they have taken the specific vulnerability of the claimant group into account. If the vulnerability of the group is deemed particularly intense, and the practices considered are not harmful for the fundamental rights of other people, state authorities must adduce stronger reasons to justify the decision not to tolerate. In that case, the practice considered might be tolerated, disregarding (that is, with no formal amendment) the rules of the Basic system, because of the particular group vulnerability.

some special consideration should be given to their needs and their different lifestyle both in the relevant regulatory planning framework and in reaching decisions in particular cases» CHAPMAN v. The UnITED KINGDOM, cit., par. 96.

65 See also the UN the 1962 Convention on Consent to Marriage, Minimum Age for Marriage, and Registration of Marriages. 


\section{Conclusion}

In that paper, I have argued for an asymmetric conception of toleration. Toleration is a form of disregard of the rules of the Basic system, for the same reasons that underpin other policies of recognition. However, reasons for toleration are not strong enough to justify a full recognition (and a subsequent accommodation) of the practices under consideration: reasons are in that case less relevant and persuasive.

Consequently, while through recognition the rules of the Basic system are modified and adapted to the new scenario (that is, to the scenario that is made different by the presence of the others), through toleration they are not: the rules of the Basic legal system remain the same, but they are partially or temporarily overcame.

A further difference is noteworthy: toleration overlooks the dialectic of reciprocity, which underpins the paradigm of recognition: toleration is required for a number of radical differences that are beyond the range of what we can recognise and accommodate, thus it is something that the majority should grant, even without asking anything (or little) in return. Toleration happens in a relationship of power imbalance: this is the reason why I have labelled toleration as a form of asymmetric relationship.

At the same time, as I have demonstrated, toleration is neither a simple act of grace, nor fully arbitrary. There are reasons that make toleration rightfully allowed, and reasons due to which toleration may not be allowed. One of these reasons -it may be the most persuasive- is the condition of particular vulnerability of the considered minority group. Only those groups that are, for different reasons, in a condition of specific vulnerability should be tolerated, and should receive special protection even beyond the limits of the policies of recognition. In other words, vulnerability may urge for toleration, even beyond the limit of what should be fully recognised and accepted in the public sphere. Of course such a condition of minority groups does not imply, per se, toleration: it merely implies that the reason not to tolerate must be examined under a closer scrutiny, and that every decision about vulnerable groups' claims should start from an aprioristic favour towards them. 